\title{
Additive effect of linseed oil supplementation on the lipid profiles of older adults
}

\author{
This article was published in the following Dove Press journal: \\ Clinical Interventions in Aging \\ 22 October 2015 \\ Number of times this article has been viewed
}

\author{
Ana Paula A Avelino' \\ Gláucia MM Oliveira' \\ Célia CD Ferreira ${ }^{2}$ \\ Ronir R Luiz \\ Glorimar Rosa ${ }^{1,4}$ \\ 'Post-Graduate Program of Medicine- \\ Cardiology, ${ }^{2}$ Department of Nutrition \\ and Dietetics, ${ }^{3}$ Institute of Public \\ Health Studies, ${ }^{4}$ Department of \\ Nutrition and Dietetics, Josué de \\ Castro Nutrition Institute, Federal \\ University of Rio de Janeiro, Rio de \\ Janeiro, Brazil
}

Background: Linseed oil has been investigated as a rich source of $n-3$ series polyunsaturated fatty acids, which mainly produce a non-atherogenic lipid profile. The objective of this study was to investigate the effect of linseed oil supplementation associated with nutritional guidelines on the lipid profiles of older adults, according to the intake of saturated fatty acids (SFA).

Methods: We conducted a double-blind, placebo-controlled clinical trial with 110 older adults randomized in two groups: placebo and linseed oil. The linseed oil group received supplementation with $3 \mathrm{~g}$ of linseed oil. Both groups received nutritional guidance and were supplemented for 90 days with monthly blood collection for biochemical analysis. The dietary intake of saturated fat was subdivided into low ( $<7 \%$ SFA/day of the total energy value) and high consumption groups ( $>7 \% \mathrm{SFA} /$ day of the total energy value).

Results: Low SFA ( $<7 \%$ SFA/day of total energy value) consumption was associated with lower total cholesterol concentrations. However, we observed that the linseed oil group, including older adults who consumed $>7 \% \mathrm{SFA} /$ day, had a greater reduction in total cholesterol than the placebo group $(P=0.020)$. The same was observed for low-density lipoprotein (LDL) cholesterol $(P<0.050)$, suggesting an additive effect of linseed oil and diet. High-density lipoprotein (HDL) cholesterol concentrations were increased significantly in only the linseed group, suggesting that the nutritional intervention alone did not improve HDL cholesterol.

Conclusion: The results suggest that the nutritional intervention was effective, but linseed oil showed notable effects by increasing the HDL cholesterol concentration. In addition, consumption of $<7 \%$ SFA/day of the total energy value increased the effect of linseed oil, demonstrating the importance of reducing the consumption of saturated fat.

Keywords: linseed oil, high-density lipoprotein cholesterol, older adults, atherosclerosis, saturated fatty acids, elderly

\section{Introduction}

Atherosclerosis is a progressive disease characterized by accumulation of lipids and fibrous components in the large arteries. It is the primary cause of coronary artery disease and stroke, which are leading causes of disability and mortality worldwide, as well as a major economic challenge for the health system. ${ }^{1}$

Altered concentrations of total cholesterol, high-density lipoprotein (HDL) cholesterol, low-density lipoprotein (LDL) cholesterol, and triglycerides are directly associated with the genesis and the evolution of atherosclerosis. ${ }^{2}$

Changes in lifestyle that emphasize food consumption are interventions used both in the long term and short term to reduce cardiovascular risk factors. ${ }^{3,4}$ Evidence indicating the effectiveness of a balanced diet with respect to the treatment and prevention of disease and the role of macronutrients and micronutrients is increasing, and these studies emphasize the role of polyunsaturated fatty acids (PUFAs), especially the n-3 series. The n-3 fatty acids include alpha linolenic acid (ALA, C18:3) of vegetable origin,
Correspondence: Glorimar Rosa Instituto de Nutrição Josué de Castro, Universidade Federal do Rio de Janeiro, Avenida Carlos Chagas Filho 373, CCS bloco J, $2^{\circ}$ andar sala 25 , Ilha do Fundão, Rio de Janeiro CEP 2194I-902, Brazil Email glorimar@nutricao.ufrj.br submit your manuscript | www.dovepress.com

Dovepress

http://dx.doi.org/10.2147/CIA.S75538 
eicosapentaenoic acid (EPA, C22:5), and docosahexaenoic acid (DHA, C22:6). ${ }^{5}$

ALA cannot be synthesized by humans, which is why its consumption through the diet is essential. Some biochemical pathways act by converting ALA into EPA and DHA, but endogenous conversion is limited in our species; between $0.2 \%$ and $8 \%$ of ALA is converted into EPA (conversion is generally higher in women of reproductive age) and between $0 \%$ and $4 \%$ of ALA is converted into DHA. ${ }^{6,7}$

Linseed oil has been investigated as a source of $n-3$ series fatty acids, which act mainly in the cardiovascular system by improving the lipid profile. ${ }^{8-10}$ Fifty percent of linseed oil is composed of PUFAs, which are one of the richest sources of ALA. ${ }^{11}$

Considering the importance of $\mathrm{n}-3$ series PUFA consumption in the diet, the purpose of this study was to investigate the effect of linseed oil supplementation associated with nutritional guidelines on the lipid profiles of older adults according to consumption of saturated fat.

\section{Subjects and methods}

\section{Trial and study groups}

We conducted a double-blind, prospective, placebo-controlled clinical trial that included 110 older adults living in Volta Redonda in the State of Rio de Janeiro. The eligibility criterion was that participants were $\geq 60$ years of age. The exclusion criteria were use of antidepressants, lipid-lowering medications, and B-complex vitamin (folate and cobalamin) supplements.

General information regarding age, smoking status, socioeconomic status, family history, clinical history, and use of supplements and medications was obtained through a structured questionnaire formulated by the researchers. The participants were randomized into two groups: a placebo + nutritional guidelines group (PG) and the linseed oil + nutritional guidelines group (LG).

\section{Ethical considerations}

The study protocol was approved by the Ethics Committee on Research on Human Beings of Clementino Fraga Filho University Hospital-UFRJ, under protocol 171/2011. The survey participants were appropriately informed about the procedures that they would undergo during the research, and an all subjects signed an informed consent form.

\section{Food consumption}

An assessment of food consumption was performed using a 24-hour recording reference method, both at the beginning and after the nutritional intervention. Food intake was assessed at the average of two 24-hour recalls at baseline, and after the nutritional intervention. The surveys were assessed by the Food Processor (2012) program. Subsequently, the stratification of saturated fat consumption was performed during the basal and post-intervention periods in accordance with the recommendations for the consumption of saturated fat, ie, less than $7 \%$ of the total daily energy value. ${ }^{10}$

\section{Assessment of physical activity}

The volunteers were told to maintain usual physical activity throughout the study, and those who were not physically active were told to continue this trend for the entire study period. Physical activity was assessed by a questionnaire pertaining to the previous month. ${ }^{11}$

\section{Clinical, anthropometric, and body composition assessments}

To assess the weight and height of the participants, we used Filizola digital scales, which have a capacity for $150 \mathrm{~kg}$ and a 100 g precision, coupled with a stadiometer. The body mass index was calculated by dividing the weight $(\mathrm{kg})$ by the height squared $\left(\mathrm{m}^{2}\right)$, considering cut-off points from the values proposed for older adults. ${ }^{12}$ The waist circumference was measured at the middle point between the last rib and the iliac crest using a non-elastic tape measure.

Body composition was assessed by a 4-pole electric bioimpedance analyzer 450e model (Biodynamics Corporation), which we also used to determine fat free mass and fat mass.

\section{Collection of blood and biochemical analyses}

Blood samples were collected in BD Vacutainer vacuum tubes with or without anticoagulant, which were centrifuged for 15 minutes at 3,000 rpm to obtain samples of plasma or serum, respectively. The concentrations of glucose and the lipid profile (triglycerides, HDL cholesterol, and total cholesterol) were measured by the enzymatic-colorimetric method using a commercial Katal kit. Very LDL (VLDL) cholesterol and LDL cholesterol values were calculated using the Friedewald equation, which is valid only if triglycerides are $<400 \mathrm{mg} / \mathrm{dL}^{13}$

\section{Supplementation and nutritional intervention}

The capsules were stored in opaque pots, which were randomly distributed in two groups. Pots containing 100 capsules 
of $500 \mathrm{mg}$ were given to the patients, who returned every two weeks for consultation and bringing the same pot for researchers count the remaining capsules and thus assess adherence to this intervention.

The placebo consisted of gelatin powder encapsulated in opaque capsules. Linseed oil supplementation consisted of oil extracted from linseed by cold pressing and encapsulating, and patients were given a total of $3 \mathrm{~g}$ of the supplement per day, which contained $1.75 \mathrm{~g}$ ALA. The amount supplemented was calculated according to the Brazilian Guideline on Dyslipidemias and Atherosclerosis Prevention-SBC. ${ }^{14}$

Both groups were given six capsules with $3 \mathrm{~g}$ of supplement or placebo per day 30 minutes before lunch and dinner, ingesting three capsules at a time. The nutritional guidelines were based on the eating habits of the volunteers, and assessments included a 24-hour food recall. The guidelines were implemented at the first consultation (T0) and strengthened in the following consultations, in accordance with the ten steps for healthy food for older adults. The goal of the ten steps is to qualitatively change the diets of older adults by adopting the following measures: reduction of the volume of meals and fractioning them into at least three meals per day; inclusion of cereals with a preference for whole grain cereals; consumption of greens and vegetables as part of the meals and fruit for dessert on a daily basis; daily consumption of skimmed milk and milk-based products, avoiding yellow cheese and butter; moderate use of vegetable oil and non-use of animal fat; avoiding sodas and artificial juices, sweet and stuffed cookies, sweet desserts and other sugary foods; reduction of the amount of salt in food, removing the salt shaker from the table; intake of at least two liters of water per day in small amounts several times per day; non-consumption of alcoholic drinks; and no smoking. ${ }^{15}$ The interventions (supplementation and nutritional guidelines) were conducted for 90 days.

\section{Statistical analysis}

The data were evaluated using Statistical Package for the Social Sciences version 17.0 software (SPSS Inc, Chicago, IL, USA), and they were expressed as the mean (standard deviation). The Shapiro-Wilk normality test was used to verify the distribution of the data. We used the chi-square test to compare differences between two groups. For comparison of quantitative variables during the study, we used a Wilcoxon's test to compare values pre-intervention and 90 days after the intervention, and the Mann-Whitney $U$-test was used for comparisons between the groups. Pearson correlation was used to determine the correlation between the variables surveyed. $P<0.05$ was considered to be statistically significant.

\section{Results}

A total of 143 volunteers were present at the beginning of the study, and $110(76.9 \%)$ were left at the end of the study. The final participants included $53(48.2 \%)$ in the PG group and $57(51.8 \%)$ in the LG group. A total of 33 volunteers withdrew from the study: eleven due to a time conflict; seven started using lipid-lowering medications; and 15 failed to attend consultations. The baseline characteristics (age, anthropometry, body composition, and biochemical data) of the volunteers who were excluded or withdrew from the study did not significantly differ from those who completed the study (Table 1). The average age of the PG participants was 66.77 (4.72) years, and the average age of the LG participants was $67.68(5.52)$ years.

Table 2 indicates the distribution of subjects with respect to the general data at the beginning of the study. Among the diseases reported by the participants, the most prevalent was systemic arterial hypertension, observed in approximately $65 \%$ of cases. All older adults participating in this study were under regular systemic arterial hypertension monitoring and received appropriate medication.

Regarding the practice of physical activity, 81.1\% (PG) and $71.9 \%$ (LG) of participants performed some sort of physical exercise, and aerobic exercises were the most frequent form, performed by $50 \%$ of the individuals in both groups. Regarding the time dedicated to physical activity, $98 \%$ of the participants spent an average of 60 minutes per day exercising. Regarding frequency, $45 \%$ of the subjects participated in physical activities three times per week.

Table I Baseline characteristics of participants ${ }^{a}$

\begin{tabular}{lll}
\hline Variables (n/\%) & $\begin{array}{l}\text { PG } \\
(\mathbf{n}=\mathbf{5 3})\end{array}$ & $\begin{array}{l}\text { LG } \\
(\mathbf{n}=\mathbf{5 7})\end{array}$ \\
\hline Female & $42(79.2 \%)$ & $49(86 \%)$ \\
Non-European & $30(56.6 \%)$ & $30(52.6 \%)$ \\
Married & $42(79.2 \%)$ & $41(7.0 \%)$ \\
Income of I-3 minimum salaries & $46(86.8 \%)$ & $52(91.2 \%)$ \\
Education for up to 9 years & $34(64.1 \%)$ & $36(68.4 \%)$ \\
Diabetes mellitus & $13(24.5 \%)$ & $17(29.8 \%)$ \\
Systemic arterial hypertension & $34(64.2 \%)$ & $37(64.9 \%)$ \\
Other* & $15(28.3 \%)$ & $23(40.4 \%)$ \\
Healthy & $8(15.1 \%)$ & $6(10.5 \%)$ \\
Smokers & $4(7.5 \%)$ & - \\
Physically active & $43(81.1 \%)$ & $41(71.9 \%)$ \\
\hline
\end{tabular}

Notes: ${ }^{T}$ There was no statistically significant difference between groups $(P>0.05)$, by chi-square test. *Other diseases included hypothyroidism $(n=21)$, hyperthyroidism $(n=11)$, arthrosis $(n=7)$, osteoporosis $(n=9)$, and Parkinson's disease $(n=1)$.

Abbreviations: LG, linseed oil + nutritional guidelines group; PG, placebo + nutritional guidelines group. 
Table 2 Baseline characteristics of the volunteers who started the study

\begin{tabular}{|c|c|c|c|c|c|c|}
\hline \multirow[t]{2}{*}{ Variable } & \multicolumn{3}{|l|}{ PG $(n=73)$} & \multicolumn{3}{|l|}{ LG $(n=70)$} \\
\hline & $\begin{array}{l}\text { Not completed } \\
(n=20)\end{array}$ & $\begin{array}{l}\text { Completed } \\
(n=53)\end{array}$ & $P$-value & $\begin{array}{l}\text { Not completed } \\
(n=13)\end{array}$ & $\begin{array}{l}\text { Completed } \\
(n=57)\end{array}$ & $P$-value \\
\hline Age (years) & $66.2 \pm 4.5$ & $66.7 \pm 4.7$ & 0.213 & $67.0 \pm 7.1$ & $67.6 \pm 5.5$ & 0.374 \\
\hline BMI $\left(\mathrm{kg} / \mathrm{m}^{2}\right)$ & $28.8 \pm 5.8$ & $28.7 \pm 4.6$ & 0.673 & $28.3 \pm 3.6$ & $28.6 \pm 5.4$ & 0.286 \\
\hline WC $(\mathrm{cm})$ & $89.4 \pm 11.6$ & $90.4 \pm 10.8$ & 0.456 & $85.1 \pm 11.9$ & $88.7 \pm 11.2$ & 0.401 \\
\hline Free fat mass $(\mathrm{kg})$ & $36.5 \pm 9.4$ & $36.5 \pm 6.9$ & 0.507 & $36.9 \pm 5.39$ & $37.2 \pm 7.5$ & 0.813 \\
\hline Glucose (mg/dL) & $93.1 \pm 29.3$ & $1 \mid 3.0 \pm 49.4$ & 0.324 & $95.7 \pm 33.5$ & $98.3 \pm 37.4$ & 0.593 \\
\hline Total cholesterol (mg/dL) & $201.3 \pm 32.4$ & $215.5 \pm 42.6$ & $0.48 \mathrm{I}$ & $200.0 \pm 42.1$ & $217.0 \pm 30.4$ & 0.859 \\
\hline LDL (mg/dL) & $|3| .1 \pm 27.2$ & $138.9 \pm 36.6$ & 0.687 & $128.5 \pm 44.0$ & $138.2 \pm 32.3$ & 0.635 \\
\hline HDL (mg/dL) & $42.7 \pm 12.9$ & $40.4 \pm 10.7$ & 0.507 & $40.8 \pm 5.5$ & $41.2 \pm 8.2$ & 0.900 \\
\hline $\operatorname{VLDL}(\mathrm{mg} / \mathrm{dL})$ & $31.84 \pm 8.14$ & $34.6 \pm 13.6$ & 0.500 & $30.5 \pm 14.5$ & $37.0 \pm 13.6$ & 0.722 \\
\hline TG (mg/dL) & $159.2 \pm 40.7$ & $173.3 \pm 68.4$ & 0.778 & $153.5 \pm 72.8$ & $184.9 \pm 68.4$ & 0.767 \\
\hline
\end{tabular}

Notes: Values expressed as mean \pm standard deviation; there was no statistical difference between the groups $(P>0.05)$ by Mann-Whitney $U$-test.

Abbreviations: BMI, body mass index; LDL, low-density lipoprotein; HDL, high-density lipoprotein; TG, triglycerides; VLDL, very low-density lipoprotein; WC, waist circumference; LG, linseed oil + nutritional guidelines group; PG, placebo + nutritional guidelines group.

Table 3 shows the participants' data regarding dietary intake of macronutrients and fatty acids during the preintervention period and after 90 days of intervention in both groups. Table 4 shows the nutritional status and lipid profile of the PG and LG groups.

In the assessment of the nutritional status of the participants, we did not find any significant differences between groups (PG and LG) or between times (before and after intervention). All participants had similar lipid profiles at the beginning of the study.

Table 4 shows the variation in lipid profile variables according to intake of saturated fatty acid (SFA) in both groups. The values for SFA intake were divided into two groups: low ( $<7 \% \mathrm{SFA} /$ day) and high $(>7 \% \mathrm{SFA} /$ day). The recommended value for SFA by the Brazilian Guideline on Dyslipidemias and Atherosclerosis Prevention-SBC is less than 7\% SFA of the total energy value (TEV) per day. Therefore, we were able to observe the dietary influence on both groups.

Regarding HDL cholesterol, the group supplemented with linseed oil showed a significant increase, suggesting that this nutritional intervention alone was not effective in improving serum HDL cholesterol levels. Older adults who had attained the recommended levels for consumption of SFA in the LG group, ie, $<7 \%$ per day, achieved a greater increase than those who consumed $>7 \%$ SFA $(P=0.045)$.

\section{Discussion}

This study is the first in Brazil to investigate the effects of linseed oil supplementation along with nutritional guidelines on older adults with the primary goal of reducing the intake of saturated fat.

Table 3 Dietary composition of participants in the PG and LG groups before and after intervention

\begin{tabular}{|c|c|c|c|c|c|c|c|}
\hline \multirow[t]{2}{*}{ Variables } & \multicolumn{3}{|l|}{ PG $(n=53)$} & \multicolumn{3}{|l|}{ LG $(n=57)$} & \multirow{2}{*}{$\frac{\Delta \text { comparisor }}{P \text {-value }}$} \\
\hline & $\begin{array}{l}\text { Before } \\
\text { intervention }\end{array}$ & $\Delta$ & $P$-value & $\begin{array}{l}\text { Before } \\
\text { intervention }\end{array}$ & $\Delta$ & $P$-value & \\
\hline Calories (kcal) & $1,369 \pm 410$ & $-167 \pm 529$ & 0.050 & $\mathrm{I}, 300 \pm 463$ & $-138 \pm 5 \mid 5$ & 0.040 & 0.524 \\
\hline Proteins (g) & $72.4 \pm 33.4$ & $-5.26 \pm 47.5$ & 0.700 & $63.7 \pm 25.2$ & $-6.4 \pm 36.3$ & 0.060 & 0.315 \\
\hline Carbohydrate (g) & $191.5 \pm 70.6$ & $-21.5 \pm 88.8$ & 0.090 & $184.5 \pm 84$ & $-22.5 \pm 99$ & 0.090 & 0.891 \\
\hline Fiber $(g)$ & $20.7 \pm 9.4$ & $-2.4 \pm 2.9$ & 0.220 & $17.9 \pm 7.7$ & $-1.2 \pm 10.4$ & 0.260 & 0.853 \\
\hline Total fat (g) & $37.7 \pm 21.2$ & $-8.1 \pm 22.8$ & 0.010 & $35.7 \pm 21.1$ & $-2.4 \pm 27$ & 0.910 & 0.283 \\
\hline Saturated fat (g) & $14.7 \pm 10.1$ & $-4.0 \pm 10.6$ & 0.001 & $12.8 \pm 8.7$ & $-2.0 \pm 10.3$ & 0.270 & 0.257 \\
\hline Mono-fat (g) & $12.9 \pm 8.7$ & $-2.7 \pm 8$ & 0.010 & $12.9 \pm 9.9$ & $-2.4 \pm 10.9$ & 0.280 & 0.312 \\
\hline Poly-fat (g) & $5.1 \pm 4.5$ & $-0.83 \pm 5.3$ & 0.520 & $5.3 \pm 3.9$ & $\mathrm{I} . \mathrm{I} \pm 5.0$ & 0.020 & $<0.001$ \\
\hline Trans-fat (g) & $1.6 \pm 3.3$ & $-0.6 I \pm 4$ & 0.090 & 2. $I \pm 4.2$ & $-10.6 \pm 55$ & 0.420 & 0.751 \\
\hline Cholesterol (g) & $176 \pm 118$ & $-32.8 \pm 156$ & 0.220 & $199 \pm 179$ & $-46.1 \pm|9|$ & 0.110 & 0.702 \\
\hline
\end{tabular}

Notes: Values expressed as the mean (standard deviation); $\Delta$, variation after 90 days of intervention; there was no statistical difference between groups during preintervention ( $P>0.05$ ); comparison before and after intervention (Wilcoxon's test); variable comparison between groups (Mann-Whitney $U$-test). Values are in bold are statistically significant.

Abbreviations: LG, linseed oil + nutritional guidelines group; PG, placebo + nutritional guidelines group. 
Table 4 Nutrition status and lipid profile of participants before and after intervention with placebo or linseed oil

\begin{tabular}{|c|c|c|c|c|c|c|c|}
\hline \multirow[t]{2}{*}{ Variables } & \multicolumn{3}{|l|}{ PG $(n=53)$} & \multicolumn{3}{|l|}{ LG $(n=57)$} & \multirow{2}{*}{$\frac{\Delta \text { comparison }}{P \text {-value }}$} \\
\hline & $\begin{array}{l}\text { Pre- } \\
\text { intervention }\end{array}$ & $\Delta$ & $P$-value & $\begin{array}{l}\text { Pre- } \\
\text { intervention }\end{array}$ & $\Delta$ & $P$-value & \\
\hline \multicolumn{8}{|c|}{ Anthropometric variables } \\
\hline $\mathrm{BMI}$ & $28.7 \pm 4.6$ & $-0.20 \pm 0.7$ & 0.060 & $28.6 \pm 5.4$ & $-0.10 \pm 0.4$ & 0.060 & 0.496 \\
\hline WC (cm) & $90.4 \pm 10.8$ & $-0.62 \pm 4.2$ & 0.390 & $88.7 \pm 11.2$ & $-0.38 \pm 3.8$ & 0.450 & 0.907 \\
\hline Free fat mass $(\mathrm{kg})$ & $45.9 \pm 9.8$ & $-0.37 \pm 3.3$ & 0.466 & $45.5 \pm 8$ & $-0.34 \pm 3.0$ & 0.500 & 0.990 \\
\hline Fat mass (\%) & $36.5 \pm 6.9$ & $0.9 \pm 4.8$ & 0.115 & $37.2 \pm 7.5$ & $0.23 \pm 4.3$ & 0.950 & 0.315 \\
\hline \multicolumn{8}{|c|}{ Biochemical variables (mg/dL) } \\
\hline $\mathrm{TC}$ & $215 \pm 42.6$ & $-28.5 \pm 32.9$ & $<0.001$ & $217 \pm 30.4$ & $-30.7 \pm 27.1$ & $<\mathbf{0 . 0 0 1}$ & 0.280 \\
\hline LDL & $139 \pm 36.6$ & $-21.7 \pm 26$ & $<0.001$ & $138 \pm 22.5$ & $-32.57 \pm 31.9$ & $<0.00 \mathrm{I}$ & 0.068 \\
\hline $\mathrm{HDL}$ & $40.4 \pm 10.7$ & $1.6 \pm 6.3$ & 0.060 & $41.2 \pm 8.2$ & $8.8 \pm 7.2$ & $<0.00$ I & $<0.001$ \\
\hline VLDL & $34.1 \pm 13.5$ & $-7.0 \pm 11.6$ & $<0.001$ & $37.0 \pm 13.6$ & $-6.8 \pm 10.9$ & $<0.00 \mathrm{I}$ & 0.808 \\
\hline TG & $170 \pm 67.6$ & $-35.2 \pm 57.9$ & $<0.001$ & $184 \pm 68.4$ & $-34.0 \pm 54.8$ & $<0.001$ & 0.829 \\
\hline
\end{tabular}

Notes: Values are expressed as the mean (standard deviation); $\Delta$, variation after 90-day intervention; comparison before and after intervention (Wilcoxon's test). Variable comparison between groups (Mann-Whitney U-test). Values are in bold are statistically significant.

Abbreviations: BMI, body mass index; LDL, low-density lipoprotein; HDL, high-density lipoprotein; TC, total cholesterol; TG, triglycerides; VLDL, very low-density lipoprotein; WC, waist circumference; LG, linseed oil + nutritional guidelines group; PG, placebo + nutritional guidelines group.

Dietary lipids are important sources of energy and precursors of many biologically active compounds. Humans can synthesize all lipids required for health, with the exception of n-3 and n-6 PUFAs, which are considered essential. When we examined PUFA consumption in older adults, we observed low food consumption. This demonstrates the need to provide linseed oil supplementation to older adults. ${ }^{16}$

We found no significant reduction in the anthropometric data in the studied groups. The reduction in calories in the diet was not sufficient to reduce weight, body fat, or waist circumference, as observed by Cassani et al. ${ }^{17}$

Studies have demonstrated a beneficial association of n-3 series fatty acid consumption and reduction of cardiovascular disease risk. ${ }^{18-20}$ Our study suggests that $3 \mathrm{~g}$ of linseed oil intake along with nutritional guidance for 12 weeks results in a significant reduction in the concentrations of total cholesterol, LDL cholesterol, and triglycerides and increased concentrations of HDL cholesterol. Regarding the placebo group, we found a significant reduction in total cholesterol, LDL cholesterol, and triglycerides; however, no change in HDL cholesterol was observed (Table 5). On the other hand, different data were found by other studies, ${ }^{17-19}$ that offered flaxseed flour in an amount ranging from 30 to $60 \mathrm{~g}$ per day for 40 to 60 days of intervention.

The relationship between dietary fat intake, dyslipidemia, and cardiovascular disease is well established. A diet rich in

Table 5 Variation of lipid profile in the PG and LG groups according to dietary intake of saturated fatty acid

\begin{tabular}{|c|c|c|c|c|c|c|}
\hline \multirow[t]{2}{*}{ Variables } & \multicolumn{3}{|l|}{ PG $(n=53)$} & \multicolumn{3}{|l|}{ LG $(n=57)$} \\
\hline & $\begin{array}{l}<\mathbf{7 \%} \text { TEV } \\
\text { saturated fat }\end{array}$ & $\begin{array}{l}>7 \% \text { TEV } \\
\text { saturated fat }\end{array}$ & $P$-value & $\begin{array}{l}<\mathbf{7 \%} \text { TEV } \\
\text { saturated fat }\end{array}$ & $\begin{array}{l}>7 \% \text { TEV } \\
\text { saturated fat }\end{array}$ & $P$-value \\
\hline \multicolumn{7}{|c|}{ Pre-intervention } \\
\hline $\mathrm{TC}$ & $218.9 \pm 41.5$ & $221.72 \pm 28.5$ & 0.09 & $213.8 \pm 43.7$ & $2|4.1 \pm 3| .7$ & 0.07 \\
\hline LDL & $145.3 \pm 38.8$ & $142.4 \pm 26.4$ & 0.10 & $135.6 \pm 35.5$ & $135.7 \pm 35.7$ & 0.09 \\
\hline $\mathrm{HDL}$ & $40.8 \pm 11.9$ & $41.6 \pm 7.9$ & 0.12 & $40.2 \pm 10.3$ & $41.0 \pm 8.5$ & 0.10 \\
\hline VLDL & $32.6 \pm 9.5$ & $37.5 \pm 12.28$ & 0.09 & $34.9 \pm 15.2$ & $36.6 \pm 14.6$ & 0.16 \\
\hline TG & $163.50 \pm 47.7$ & $174.6 \pm 76.2$ & 0.07 & $|87.7 \pm 6| .8$ & $|83.2 \pm 7| . \mid$ & 0.08 \\
\hline \multicolumn{7}{|c|}{ Post-intervention } \\
\hline $\mathrm{TC}$ & $|84.1 \pm 3| .0^{\mathrm{a}}$ & $199.2 \pm 18.6^{\mathrm{a}}$ & 0.03 & $181.5 \pm 23.3^{\mathrm{a}}$ & $183.2 \pm 23.8^{\mathrm{a}}$ & 0.12 \\
\hline LDL & $|28.4 \pm 3| .02^{\mathrm{a}}$ & $114.4 \pm 22.3^{\mathrm{a}}$ & 0.04 & $103.3 \pm 23.2^{\mathrm{a}}$ & $102.3 \pm 22.9^{a}$ & 0.05 \\
\hline HDL & $40.23 \pm 11.0$ & $43.9 \pm 6.5$ & 0.09 & $50.8 \pm 6.1^{\mathrm{a}}$ & $48.0 \pm 7.3^{\mathrm{a}}$ & 0.04 \\
\hline VLDL & $28.7 \pm 9.4$ & $31.4 \pm 7.5$ & 0.11 & $26.2 \pm 8.8$ & $29.4 \pm 9.0$ & 0.06 \\
\hline TG & $127.0 \pm 47.1^{\mathrm{a}}$ & $142.4 \pm 44 . I^{\mathrm{a}}$ & 0.08 & $|4| .8 \pm 37.8^{\mathrm{a}}$ & $159.7 \pm 45.0^{a}$ & 0.02 \\
\hline
\end{tabular}

Notes: Values are expressed as the mean (standard deviation); $\Delta$, variation after 90 -day intervention; asignificant difference between before and after intervention; comparison before and after intervention (Wilcoxon's test); variable comparison between groups (Mann-Whitney U-test).

Abbreviations: LDL, low-density lipoprotein; HDL, high-density lipoprotein; TC, total cholesterol; TG, triglycerides; VLDL, very low-density lipoprotein; LG, linseed oil + nutritional guidelines group; PG, placebo + nutritional guidelines group; TEV, total energy value. 
saturated and total fat contributes to elevated concentrations of total cholesterol and LDL cholesterol. Reduction of fat in the diet is one of the fundamental objectives in the treatment of dyslipidemia. ${ }^{20}$ On the other hand, polyunsaturated fats have been related to a decrease in concentrations of triglycerides, total cholesterol, and LDL cholesterol and an increase in HDL cholesterol concentrations. ${ }^{21}$

This study emphasizes the effect of the dietary influence of saturated fat on serum concentrations of lipids for subjects who consumed $<7 \% \mathrm{SFA} /$ day of the TEV because the results were higher than for those individuals who consumed $>7 \%$ SFA/day of the TEV, and this response was even better with linseed oil supplementation. This finding demonstrates the importance of the quality of lipid in the diet, ie, a reduction of SFA and an increase in PUFAs.

According to Flowers et al individuals, especially men, with low concentrations of HDL cholesterol $(<40 \mathrm{mg} / \mathrm{dL}$ in men and $<50 \mathrm{mg} / \mathrm{dL}$ in women) are at higher risk for coronary disease, restenosis after angioplasty, and cardiovascular death. ${ }^{22}$ Siddiqi et al suggested that an increase of $1 \mathrm{mg} / \mathrm{dL}$ in the concentration of HDL cholesterol is associated with a $6 \%$ decrease in the risk of death caused by coronary artery disease or a heart attack. ${ }^{23}$

Few studies on the effect of flaxseed oil supplementation in adults have been performed, and there is no consensus as to the supplementation amount; however, most studies use high dosages. For example, Gillingham et al conducted a randomized trial with 36 hypercholesterolemic adults using three types of hyperlipid diets for 28 days. Approximately $36 \%$ of the energy in each diet was from fat, of which $70 \%$ was provided by canola oil or flaxseed oil mixed with canola oil or a typical Western diet. After 28 days, they concluded that the intake of canola oil, with or without flaxseed oil, reduced of LDL-cholesterol and increasedHDL-cholesterol levels $(P<0.001){ }^{22}$

In the study conducted by Gillingham et al a diet with a low content of SFA and a high content of PUFA was used along with linseed oil mixed with canola oil in high concentrations. Although they achieved a reduction in the concentration of LDL cholesterol and an increase in HDL cholesterol, our study, even using low concentrations of linseed oil and nutritional guidelines, showed the same result. ${ }^{22}$

This difference causes us to question whether supplementation with n-3 in high dosages is really necessary. Studies using linseed oil (20-40 g/day) have shown a significant effect on lipid concentrations. ${ }^{23,24}$ However, these dosages would require the intake of 9-40 capsules/day. Ingestion of this large amount of capsules is not practical from a clinical point of view because healthy individuals tend to consume two capsules/day. ${ }^{24}$ In addition, high doses may not be well tolerated, causing halitosis and reflux, resulting in low adherence. ${ }^{24}$

Our study used $3 \mathrm{~g} /$ day of linseed oil for 12 weeks. This procedure significantly increased HDL cholesterol and was a viable choice regarding the number of capsules consumed because there were no reports of intolerance of the capsules. At the same time, this method may be an alternative for people sensitive to the chemical composition of fish oil.

However, Kaul et al aimed to compare the effect of different dietary oils (fish, linseed, and hemp) in small dosages with respect to cardiovascular parameters. They performed a randomized, double-blind, placebo-controlled clinical trial with 86 healthy volunteers over 12 weeks. Both groups received supplementation with two capsules ( $2 \mathrm{~g} /$ day $)$. The concentrations of total cholesterol, LDL cholesterol, HDL cholesterol, and triglycerides indicated no significant difference between groups or between the baseline time and after the intervention. They concluded that ingesting only $2 \mathrm{~g}$ of both oils did not provide the expected result over a 3-month period. ${ }^{25}$

A study using EPA and DHA ${ }^{24}$ supplementation showed similar results to ours. Some studies have reported that the conversion of ALA to EPA and DHA is reduced in humans, ${ }^{6,7}$ and we cannot rule out that in small proportions, this conversion is possible.

We must emphasize that further studies should be conducted with linseed oil to assess the reproducibility of these findings in larger populations. It is important to evaluate the conversion of ALA to EPA and DHA to increase knowledge of the beneficial effects of this pathway, such as improvement in HDL cholesterol concentrations. ${ }^{26,27}$

In addition, we have to take into consideration the limitations encountered during the intervention because there was a significant loss of sample participants. The participants had very busy schedules, which hindered the consultations that took place every 15 days, even when participants were offered alternative schedules.

\section{Conclusion}

These results reinforce the importance of nutrition in lifestyle modifications in older adults. Despite the high prevalence of physical activity, which is strongly correlated with an improved lipid profile, the participants had similar values in all concentrations of lipid fractions. It is noteworthy that the nutritional guidance alone was efficient; however, the linseed oil was notable mainly in increasing HDL cholesterol concentrations. Furthermore, it was possible to observe that the intake of saturated fat, ie, $<7 \%$ per day of the TEV, 
enhanced the effect of linseed oil, demonstrating once again the importance of a balanced diet.

\section{Acknowledgments}

The authors are grateful to the Foundation for Research Support of the State of Rio de Janeiro and the National Council for Scientific and Technological Development for financially supporting this study and to Cisbra for donation of the flaxseed oil.

\section{Disclosure}

The authors declare no financial or personal conflict of interest with regard to the present study.

\section{References}

1. Rodriguez-Leyva D, Dupasquier CM, McCullough R, et al. The cardiovascular effects of flaxseed and its omega-3 fatty acid, alpha-linolenic acid. Can J Cardiol. 2010;26(9):489-496.

2. World Health Organization. World Health Statistics 2011. Available from: http://www.who.int/whosis/whostat/. Accessed July 19, 2015.

3. Fukumitsu S, Aida K, Shimizu H, et al. Flaxseed lignan lowers blood cholesterol and decreases liver disease risk factors in moderately hypercholesterolemic men. Nutr Res. 2010;30(7):441-446.

4. Goff DC Jr, Lloyd-Jones DM, Bennett G, et al. 2013 ACC/AHA guideline on the assessment of cardiovascular risk: a report of the American College of Cardiology/American Heart Association Task Force on Practice Guidelines. Circulation. 2014;129(25 Suppl 2):S49-S73.

5. Mozaffarian D, Wu JH. Omega-3 fatty acids and cardiovascular disease: effects on risk factors, molecular pathways, and clinical events. $J \mathrm{Am}$ Coll Cardiol. 2011;58(20):2047-2067.

6. Hunter JE, Zhang J, Kris-Etherton PM. Cardiovascular disease risk of dietary stearic acid compared with trans, other saturated, and unsaturated fatty acids: a systematic review. Am J Clin Nutr. 2010;91(1):46-63.

7. Xu J, Yang W, Deng Q, Huang Q, Yang J, Huang F. Flaxseed oil and $\alpha$-lipoic acid combination reduces atherosclerosis risk factors in rats fed a high-fat diet. Lipids Health Dis. 2012;31(11):148-155.

8. Kontogianni MD, Vlassopoulos A, Gatzieva A, et al. Flaxseed oil does not affect inflammatory markers and lipid profile compared to olive oil, in young, healthy, normal weight adults. Metabolism. 2013;62(5):686-693.

9. Tomaz Pacheco J, Beltrame Daleprame J, Teles Boaventura G. [Impact of dietary flaxseed (Linum usitatissimum) supplementation on biochemical profile in healthy rats]. Nutr Hosp. 2011;26(4):798-802. Spanish.

10. ESHA Research. Food Processor Nutrition Analysis System. Salem, OR, USA: ESHA Corporation; 2012.

11. Gomes VB, Siqueira KC, Sichieri R. [Physical activity in a probabilistic sample in the city of Rio de Janeiro]. Cad Saude Publica. 2001;17(4): 969-976. Portuguese.

12. The Nutrition Screening Initiative. Incorporating Nutrition Screening and Interventions into Medical Practice: A Monograph for Physicians. Washington, DC, USA: American Academy of Family Physicians, American Dietetic Association, National Council on Aging Inc; 1994.
13. Friedewald WT, Levy RI, Fredrickson DS. Estimation of the concentration of low-density lipoprotein cholesterol in plasma, without use of the preparative ultracentrifuge. Clin Chem. 1972;18(6):499-502.

14. Xavier HT, Izar MC, Faria Neto JR, et al. Brazilian Guidelines on Dyslipidemia and Prevention of Atherosclerosis. [Diretriz Brasileira de Dislipidemias e Prevenção da Aterosclerose]. Arq Bras Cardiol. 2013;101(4):1-22. Portuguese.

15. Brazil. Ministry of Health, Department of Health Care, Department of Primary Care. Healthy eating for the elderly: a handbook for health professionals/Ministry of Health, Ministry of Health Care, Department of Primary Care - Brasília: Editora do Ministério da Saúde, 2009. Available from: http://bvsms.saude.gov.br/bvs/publicacoes/alimentacao_saudavel_idosa_profissionais saude.pdf. Accessed September 3, 2015.

16. De Lira-García C, Bacardí-Gascón M, Jiménez-Cruz A. [Effectiveness of long-term consumption of nuts, seeds and seeds' oil on glucose and lipid levels; systematic review]. Nutr Hosp. 2012;27(4):964-970. Spanish.

17. Cassani RS, Fassini PG, Silvah JH, Lima CM, Marchini JS. Impact of weight loss diet associated with flaxseed on inflammatory markers in men with cardiovascular risk factors: a clinical study. Nutr J. 2015;14: $5-13$.

18. Torkan M, Entezari MH, Siavash M. Effect of flaxseed on blood lipid level in hyperlipidemic patients. Rev Recent Clin Trials. 2015;10(1): 61-67.

19. Khalatbari Soltani S, Jamaluddin R, Tabibi H, et al. Effects of flaxseed consumption on systemic inflammation and serum lipid profile in hemodialysis patients with lipid abnormalities. Hemodial Int. 2013;17(2): 275-281.

20. Santos RD, Gagliardi ACM, Xavier HT, et al. [Sociedade Brasileira de Cardiologia. I Diretriz sobre o consumo de Gorduras e Saúde]. Nutr Hosp. 2013;100(3):1-40. Spanish.

21. Wei MY, Jacobson TA. Effects of eicosapentaenoic acid versus docosahexaenoic acid on serum lipids: a systematic review and meta-analysis. Curr Atheroscler Rep. 2011;13(6):474-483.

22. Flowers E, Molina C, Mathur A, Reaven GM. Use of plasma triglyceride/high-density lipoprotein cholesterol ratio to identify increased cardio-metabolic risk in young, healthy South Asians. Indian J Med Res. 2015;141(1):68-74.

23. Siddiqi HK, Kiss D, Rader D. HDL-cholesterol and cardiovascular disease: rethinking our approach. Curr Opin Cardiol. 2015;30(5): 536-542.

24. Gillingham LG, Robinson KS, Jones PJ. Effect of high-oleoc canola and flaxseed oils on energy expenditure and body composition in hypercholesterolemic subjects. Metabolism. 2012;61(11):1598-1605.

25. Kuipers RS, de Graaf DJ, Luxwolda MF, et al. Saturated fat, carbohydrates and cardiovascular disease. The Netherlands Journal of Medicine. 2011;69(9):372-378.

26. Wei MY, Jacobson TA. Effects of eicosapentaenoic acid versus docosahexaenoic acid on serum lipids: A systematic review and meta-analysis. Current Atherosclerosis Report. 2011;13(6):474-483.

27. Kaul N, Kreml R, Austria JA, et al. A comparison of fish oil, flaxseed oil and hempseed oil supplementation on selected parameters of cardiovascular health in healthy volunteers. Journal of the American College of Nutrition. 2008;27(1):51-58.
Clinical Interventions in Aging

\section{Publish your work in this journal}

Clinical Interventions in Aging is an international, peer-reviewed journal focusing on evidence-based reports on the value or lack thereof of treatments intended to prevent or delay the onset of maladaptive correlates of aging in human beings. This journal is indexed on PubMed Central, MedLine,

\section{Dovepress}

CAS, Scopus and the Elsevier Bibliographic databases. The manuscript management system is completely online and includes a very quick and fair peer-review system, which is all easy to use. Visit http://www.dovepress. com/testimonials.php to read real quotes from published authors. 